\title{
Importance of Teaching Medical Ethics at Undergraduate Level in Medical Colleges Dr. Farah Amir Ali
}

Advancement of science and technology including storm of social media, has developed many challenges for healthcare providers more than ever. In every day practice medical professionals face many situations where decisions are not merely taken on clinical and technical grounds but also require sound knowledge of ethics. In order to justify individual actions in particular situation, the code of conduct is always there. The importance of understanding medical ethics is undeniable due to increasing litigations and complexities in medical practice. On the other hand, majority of population is depending on doctors who are not adequately trained for medical ethics and professionalism. Medical ethics has become core part of medical education in worldwide but in our scenario, it seems to be left alone on personal opinions and routine practices. Our current undergraduate medical curriculum is still deficient in providing proper frame work to cover medical ethics. Few reasons that we still lack well defined curriculum are shortage of time, lack of qualified experts and deficiency of realizing its importance in providing quality care to patients. Due to which it has been found that graduates face problem in dealing with situations of medico-legal and ethics. ${ }^{1}$ Medical ethics has been defined as "the analytical activity in which the concepts, assumptions, beliefs, attitudes, emotions, reasons, and arguments underlying medico-moral decision making are examined critically." research ethics. The six common values that apply to medical ethics are autonomy, beneficence, nonmaleficence (first do not harm), justice, dignity, truthful, and honesty ${ }^{3}$. These mentioned norms themselves are not sufficient to deal with a particular situation. Medical ethics is well defined curriculum which includes core topics ranges from informed consent to refusal of treatment, rights, confidentiality, good practices and vulnerabilities created by doctors and students etc. Although it is obligatory to health care provider that adequate information is given to patients for treatment and procedure. They are also aware of potential benefits and risks of the given treatment. ${ }^{4}$ Currently the curriculum which is taught in our medical colleges is aligned according to the prescribed text

\section{Correspondence:}

Dr. Farah Amir Ali

Email: farah.zulfiqar@yahoo.com books of west, which often does not meet the need of our community. As knowledge is expanding so rapidly, there is necessity that we in Pakistan revise our curriculum according to local context and omit unnecessary cramming components and replace it with more practical approaches which help in developing community doctor, who can rationally treat patient. Ethics and professionalism should be included as the core part of syllabus in spiral manner so that our medical graduates are skilled enough to manage risky situations and have good communication and inter personal skills. There are multiple justifications that we should consider teaching ethics at undergraduate level. It would be helpful in resolving disputes among doctors, patients and relatives. It would give insight to make decisions beyond personal values and emotions on ethical codes. On the other hand, it is equally important to maintain fair relationship with other clinicians. It provides means of creating virtuous and skillful doctors for evaluating and resolving ethical dilemmas. Teaching ethics may deal to reduce cynicism in medical students and also help to abate ethical erosion as they progress in their careers. In developed countries like Canada, USA, UK, this course is integral part of their curriculum and it is evident from several researches that teaching ethics at undergraduate, has positive impact. It increases the decision-making abilities and contribute in daily working of medical professionals. We cannot teach their ethics as our religious and cultural context is entirely different from western world. So, we need to develop medical ethics curriculum along with its compulsory examination to assess the ability of students to critically and logically make decisions on ethical issues. It is the demand of time that we work altogether to train "community friendly ethical health care provider" to improve our healthcare system.

\section{Conflict of interest: None}

\section{REFERENCES:}

1. Ahsin S, Shahid A, Gondal GhM. Teaching communication skills and medical ethics to undergraduate. J. Adv Med \& Prof. 2013;1(3):72-76.

2. Pasha HC, Ali M. Principles of Islamic Medical Ethics JBIMA. 2019;1 (1). https://jbima. com/article / principles-of-islamic-medical-ethics. [cited on:August 23,2020]

3. Beauchamp TL, Childress JF. Principles of biomedical ethics. 5th ed. Oxford University Press; 2001.454. ISBN 0-19-514332-9 https://jme.bmj.com/content/28/5/332.2.[cited on: August223,2020] 
4. Health ethics in practice: key issues and challenges. Global health ethics key issues Global Network of WHO Collaborating Centers for Bioethics World Health Organization. 2015 